\title{
INTERVALO HÍDRICO ÓTIMO E POROSIDADE DE SOLOS CULTIVADOS EM ÁREA DE PROTEÇÃO AMBIENTAL DO SUL DE MINAS GERAIS ${ }^{(1)}$
}

\author{
Vico Mendes Pereira Lima ${ }^{(2)}$, Geraldo César de Oliveira ${ }^{(3)}$, Eduardo \\ da Costa Severiano ${ }^{(4)} \&$ Luiz Fernando Coutinho de Oliveira ${ }^{(5)}$
}

\begin{abstract}
RESUMO
Condições físicas restritivas ao adequado desenvolvimento das plantas reduzem a capacidade produtiva dos solos e a sustentabilidade ambiental. Um importante parâmetro para expressar essas restrições é o intervalo hídrico ótimo (IHO), por representar, conjuntamente, atributos físicos do solo que influenciam o desenvolvimento de plantas. Com o objetivo de avaliar o IHO e a porosidade de solos cultivados com café e pastagem na microbacia do ribeirão Capituvas, local representativo da APA Coqueiral, coletaram-se amostras indeformadas no Latossolo Vermelho distrófico típico (LVd), no Argissolo Vermelho eutrófico típico (PVe) e no Cambissolo Háplico distrófico típico (CXbd), nas camadas de 0-5, 20-25 e 40$45 \mathrm{~cm}$, respectivamente. Os poros com diâmetro $>145 \mu \mathrm{m}$ foram os mais afetados pelo manejo. Apesar de não haver diferenças entre os microporos (poros com diâmetro $<50 \mu \mathrm{m}$, responsáveis pela água potencialmente disponível para as plantas), observaram-se variações no IHO, sendo no LVd $>$ CXbd $>$ PVe. Conclui-se que o IHO é um parâmetro que pode ser utilizado com segurança na quantificação das alterações que ocorrem na disponibilidade de água dos solos submetidos a diferentes usos e manejos.
\end{abstract}

Termos de indexação: compactação, sustentabilidade ambiental, disponibilidade hídrica do solo.

\footnotetext{
(1) Parte da Dissertação do primeiro autor apresentada ao Programa de Pós-Graduação em Ciência do Solo da Universidade Federal de Lavras - UFLA. Recebido para publicação em outubro de 2008 e aprovado em novembro de 2009.

${ }^{(2)}$ Doutorando, Departamento de Ciência do Solo, Universidade Federal de Lavras - UFLA. Caixa Postal 3037, CEP 37200-000 Lavras (MG). Bolsista da FAPEMIG. E-mail: vicomendes@hotmail.com

(3) Professor adjunto do Departamento de Ciência do Solo, UFLA. E-mail: geraldooliveira@dcs.ufla.br

(4) Doutorando, Departamento de Ciência do Solo, UFLA. Bolsista do CNPq. E-mail: severianoec@yahoo.com.br

(5) Professor associado do Departamento de Engenharia, UFLA. Bolsista do CNPq. E.mail: lfco@pq.cnpq.br
} 


\title{
SUMMARY: LEAST LIMITING WATER RANGE AND POROSITY OF CULTIVATED SOILS IN AN ENVIRONMENTAL PROTECTION AREA IN THE SOUTH OF MINAS GERAIS
}

\begin{abstract}
Restrictive physical conditions for an adequate plant development reduce the productive capacity of soils and environmental sustainability. An important parameter to express these restrictions is the least limiting water range (LLWR), which is used in combination with soil physical properties that influence plant development. To evaluate the LLWR and porosity of soils under coffee and pasture in the Capituvas River microbasin, a representative area of the Coqueiral Resereve was chosen. Undisturbed samples of a typical Dystrophic Red Latosol (LVd-Oxisol), typical Eutrophic Red Argisol (PVe-Ultisol) and typical Dystrophic Haplic Cambisol (CXbd-Inceptisol) were collected from the layers 0-5, 20-25 and 40-45 cm. Pores with a diameter of $>145 \mu \mathrm{m}$ were most affected by the management. Although no statistical differences were verified among the micropores (pores $<50 \mu \mathrm{m}$ ), variations occurred in $L L W R$, in the following order: $L V d>C X b d>P V e$. It is possible to conclude that $L L W R$ is a reliable parameter that could be used to quantify alterations that occur in the water availability of soils under different use and management systems.
\end{abstract}

Index terms: compaction, environmental sustainability, soil water availability.

\section{INTRODUÇÃO}

As pesquisas em áreas de proteção ambiental (APAs) estão sendo desenvolvidas para dar suporte a alternativas tecnológicas que possibilitem o uso racional dos recursos naturais. Nestas unidades de conservação têm se conseguido importantes resultados relacionados à conservação da diversidade de ambientes, espécies e processos naturais e adequação das atividades humanas às características ambientais.

No município de Coqueiral, região sul de Minas Gerais, cerca de $25 \%$ do território foi destinado à criação de uma Área de Proteção Ambiental (APA Coqueiral), por estar localizada no entorno da represa de Furnas e ser local rico em nascentes e cursos d'água. Além da preservação dos recursos naturais, a área sustenta aproximadamente 400 famílias, cuja fonte de renda baseia-se principalmente na cafeicultura e pecuária (Emater, 2002).

O estudo das potencialidades e limitações físicas dos solos em APAs é de grande importância na busca da sustentabilidade de uso e manejo das terras. Condições físicas dos solos que afetam o crescimento das plantas estão diretamente relacionadas à resistência do solo à penetração de raízes, a disponibilidade de água e a aeração, os quais afetam diretamente a produtividade agrícola (Silva et al., 1994) e a sustentabilidade do ambiente. Neste contexto, o intervalo hídrico ótimo (IHO) vem ganhando notoriedade, por aliar num único parâmetro, atributos físicos relacionados à qualidade do solo, sendo o indicador que melhor se correlaciona com o crescimento das plantas (Tormena et al., 2007).

Trabalhos que avaliam o IHO, e consequentemente a porosidade, são utilizados na física do solo para monitorar sistemas de preparo e uso do solo, de três formas distintas: (1) avaliar a qualidade física para o crescimento vegetal (Tormena et al., 2007; Severiano et al, 2009); (2) estabelecer relações entre este indicador e o crescimento da parte aérea das plantas (Silva \& Kay, 1996); (3) investigar relações funcionais entre IHO e produtividade de grãos (Lapen et al., 2004; Beutler et al., 2008).

A diminuição da amplitude do IHO indica o aumento da exposição das culturas ao estresse hídrico e a magnitude na qual a condição estrutural do solo restringe o desenvolvimento das plantas (Silva \& Kay, 1997). Em solos com avançado grau de compactação, a aeração se torna deficiente em elevados conteúdos de água, e a resistência à penetração poderá restringir o desenvolvimento das plantas com o secamento do solo (Lapen et al., 2004), reduzindo então o conteúdo de água potencialmente disponível para as plantas.

As alterações estruturais decorrentes do manejo inadequado também alteram a distribuição de tamanho e continuidade de poros (Oliveira et al., 2004) e modifica, consequentemente, a dinâmica da água no solo relacionada à infiltração e recarga do lençol freático (Reichert et al., 2007). Como resultado, o solo perde sua capacidade produtiva e tem a susceptibilidade à erosão aumentada, podendo desencadear perdas irreversíveis ao ambiente.

As alterações estruturais dos solos em áreas de proteção ambiental resultam em restrições ao crescimento das plantas, ao aumento da erosão e à diminuição da produção de água na bacia hidrográfica, desencadeando o processo degradativo dessas áreas essenciais para a sustentabilidade do ambiente.

Objetivou-se, com esta pesquisa, avaliar o intervalo hídrico ótimo e a porosidade de solos cultivados com café e pastagem na microbacia do ribeirão Capituvas, local representativo da APA Coqueiral. 


\section{MATERIAL E MÉTODOS}

A pesquisa foi realizada na microbacia do ribeirão Capituvas, localizada na Área de Proteção Ambiental do município de Coqueiral, MG (APA Coqueiral), localizado no sul de Minas Gerais. O clima local é classificado, segundo Köppen, como Cwa de verão brando e chuvoso, com temperatura moderada, média anual de $21^{\circ} \mathrm{C}$. A precipitação média anual é de $1.500 \mathrm{~mm}$ e a média anual de umidade relativa do ar é de $70 \%$ (Emater, 2002).

Na condução deste estudo, selecionou-se a microbacia do ribeirão Capituvas, por ser representativa da APA Coqueiral nos aspectos referentes a usos, relevo e classes de solo. Aárea estudada possui na sua maioria solos rasos e originados do intemperismo de rochas graníticas do período pré-cambriano (Brasil, 1962). O relevo, já bastante dissecado pela erosão hídrica, é predominantemente ondulado formado por superfícies com pedoforma, variando de convexa a côncava nos topos de morros e nos fundos dos vales, respectivamente.

Utilizando o Manual de Descrição e Coleta de Solo no Campo (Santos et al., 2005), os solos foram classificados segundo o Sistema Brasileiro de Classificação dos Solos (Embrapa, 2006), em Cambissolo Háplico distrófico típico (CXbd) de textura média, ocupando $51 \%$ da área, seguido pelo Argissolo Vermelho eutrófico típico (PVe) de textura médial argilosa (33 \%) e pelo Latossolo Vermelho distrófico típico (LVd) de textura argilosa (8\%). Além desses solos, encontram-se na microbacia Neossolo Litólico associados a afloramentos rochosos e solos indiscriminados de várzea ao longo da rede de drenagem, que ocupam $8 \%$ da área (Figura 1). A caracterização física e química desses solos encontrase no quadro 1.

A pesquisa foi realizada em $\mathrm{LVd}$, PVe e CXbd cultivados com café e pastagem (Brachiaria decumbens), pertencentes a agricultores que adotam manejos diferenciados. As culturas de café e pastagem representam, respectivamente, 8 e $84 \%$ da cobertura vegetal da microbacia. Esses solos vêm sendo cultivados a aproximadamente oito anos, sendo anteriormente utilizados com pastagem nativa. Por ocasião da implantação das culturas, houve o revolvimento do solo. A área de LVd possui terraços, mas o produtor não implantou a cultura de café em nível e nem adota nenhuma outra prática de conservação do solo. No PVe, o produtor não adota práticas de conservação do solo e o manejo é inadequado, razão por que a lavoura de café está depauperada e a pastagem degradada. No CXbd, além do terraceamento e implantação da lavoura de café em nível, o produtor faz o manejo adequado do mato, utilizando-se de culturas de cobertura com capinas alternadas nas entrelinhas da lavoura; na área de pastagem o manejo é adequado, com exceção de uma pequena gleba degradada em função da água proveniente da estrada. Todos os produtores se utilizam de práticas manuais na condução das lavouras de café.

Foram coletadas, em cada solo, amostras indeformadas em seis pontos diferentes, sendo três na área cultivada com café e três na área de pastagem. Utilizando-se o amostrador de Uhland, amostras de solo foram coletadas em anéis volumétricos de $6,40 \mathrm{~cm}$ de diâmetro e $2,50 \mathrm{~cm}$ de altura nas camadas de $0-5$, 20-25 e 40-45 cm de profundidade em cada solo com seu respectivo uso totalizando 162 amostras (3 solos $\mathrm{x}$ 2 usos $\mathrm{x} 3$ camadas $\mathrm{x} 3$ pontos $\mathrm{x} 3$ repetições).

Para a determinação do intervalo hídrico ótimo (IHO), foi necessária a determinação das curvas de retenção de água e da resistência do solo à penetração (RP). A RP foi determinada utilizando-se penetrógrafo eletrônico modelo MA 933, marca Marconi, com velocidade constante de $10 \mathrm{~cm} \mathrm{~min}{ }^{-1}$. Foram realizadas quatro avaliações por amostra em diferentes conteúdos

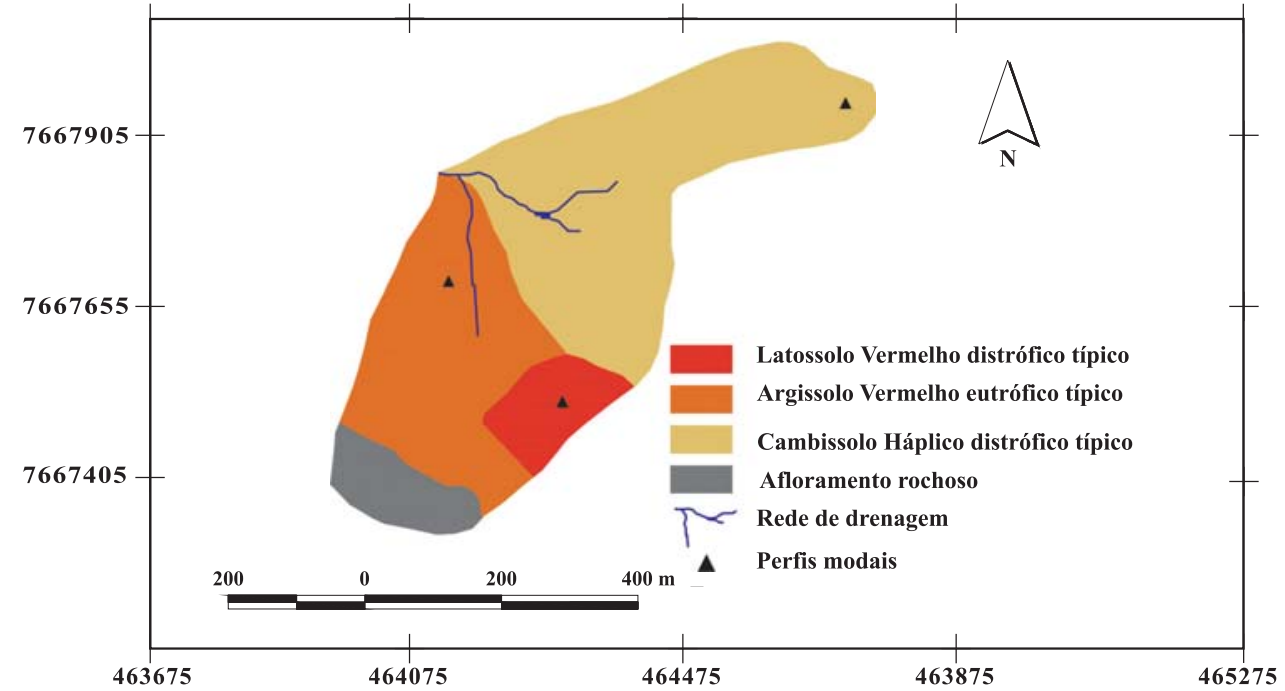

Figura 1. Mapa de solos da microbacia do ribeirão Capituvas, APA Coqueiral. Área total de 33,8 ha. 
Quadro 1. Caracterização física e química dos solos da microbacia do ribeirão Capituvas, APA Coqueiral

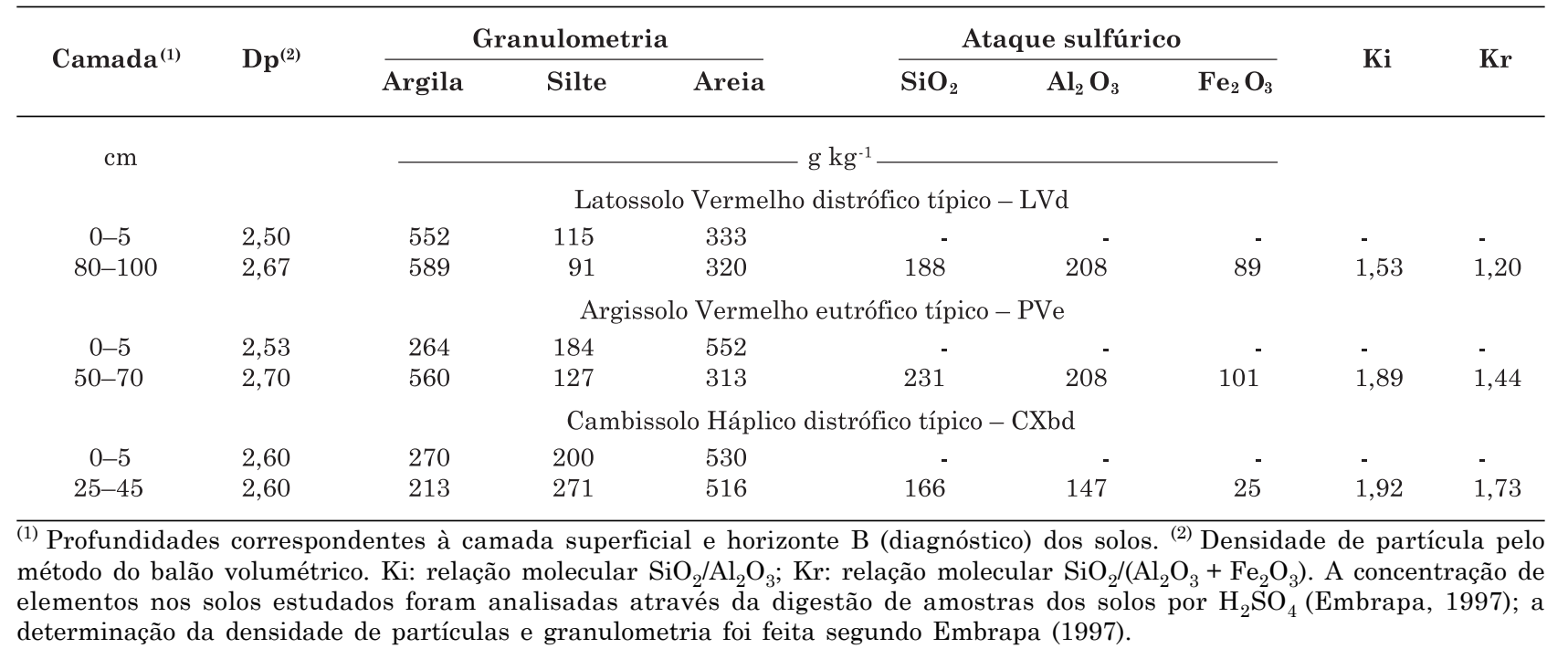

de água, ajustados com base na curva de retenção. Após os testes, as amostras foram secas em estufa a $105^{\circ} \mathrm{C}$, por $48 \mathrm{~h}$, para a determinação da densidade do solo. Os valores de RP, obtidos em $\mathrm{kgf} \mathrm{cm}^{-2}$, foram multiplicados pelo fator 0,098 para a transformação em MPa e ajustados a modelos não lineares, em função do conteúdo volumétrico de água $(\theta)$, utilizando-se a equação 1 (Dias Junior, 1994) e o software Sigma Plot 10.0 (2006).

$$
R P=10^{(a+b \theta)}
$$

sendo $\mathrm{RP}$ a resistência à penetração $(\mathrm{MPa}) ; a$ e $b$ os parâmetros de ajuste da equação e $\theta$ o conteúdo volumétrico de água $\left(\mathrm{cm}^{3} \mathrm{~cm}^{-3}\right)$.

O volume total de poros (VTP) foi determinado segundo Embrapa (1997), pela equação 2:

$$
V T P=1-(D s / D p)
$$

sendo Ds a densidade do solo $\left(\mathrm{g} \mathrm{cm}^{-3}\right)$ e Dp a densidade de partícula $\left(\mathrm{g} \mathrm{cm}^{-3}\right)$.

$\mathrm{Na}$ determinação da curva de retenção de água (CRA), utilizaram-se seis amostras por camada de solo, três referentes à área cultivada com café e três referentes à área cultivada com pastagem. Considerando-se a profundidade do solo e o uso (3 solos x 2 usos x 3 camadas x 3 repetições), totalizaram-se 54 amostras. As amostras indeformadas foram inicialmente saturadas em bandejas até $2 / 3$ da altura e submetidas a tensões de -2, -4, -6 e -10 kPa na coluna de sucção (Reinert \& Reichert, 2006). As amostras deformadas, obtidas das sobras das porções superiores e inferiores de cada anel, foram também saturadas e submetidas a tensões de -33, -100, -500 e $-1.500 \mathrm{kPa}$, nos aparelhos extratores de Richards (Embrapa, 1997).
A CRA foi obtida ajustando-se o conteúdo volumétrico de água $(\theta)$ em função da tensão da água no solo (h), utilizando procedimento de van Genuchten (1980), com o uso do software SWRC (Dourado Neto et al., 2000), conforme equação 3:

$$
\theta=\left(\theta_{\text {sat }}-\theta_{\text {res }}\right)\left[1+(\theta h)^{n}\right]^{-m}+\theta_{\text {res }}
$$

sendo h a tensão da água no solo $(\mathrm{kPa}) ; \theta$ o conteúdo de água $\left(\mathrm{cm}^{3} \mathrm{~cm}^{-3}\right) ; \theta_{\text {sat }}$ o conteúdo de água na saturação $\left(\mathrm{cm}^{3} \mathrm{~cm}^{-3}\right) ; \theta_{\text {res }}$ o conteúdo de água no ponto de murcha permanente $\left(\mathrm{cm}^{3} \mathrm{~cm}^{-3}\right) ; \mathrm{m}, \mathrm{n}$ e $\theta$ os parâmetros de ajuste do modelo.

O ponto de inflexão da curva característica de água no solo foi determinado pela segunda derivada da equação 3, e o valor obtido considerado a capacidade de campo do solo (Ferreira \& Marcos, 1983; Mello et al., 2002). Assim, a tensão da água no solo no ponto de inflexão foi determinada pela equação 4, utilizando a regra da cadeia no processo de derivação (Dexter, 2004):

$$
h=1 / \alpha(1 / m)^{1 / n}
$$

sendo h a tensão da água no solo no ponto de inflexão $(\mathrm{kPa})$ e $\mathrm{m}, \mathrm{n}$ e $\theta$ os parâmetros de ajuste do modelo.

$\mathrm{Na}$ determinação dos limites superiores do IHO, considerou-se o conteúdo de água no solo na capacidade de campo $\left(\theta_{\mathrm{CC}}\right)$, ou aquele em que a porosidade de aeração $\left(\theta_{\mathrm{PA}}\right)$ é considerada adequada ao desenvolvimento da cultura. Os limites inferiores foram considerados o conteúdo de água no solo correspondente ao ponto de murcha permanente $\left(\theta_{\mathrm{PMP}}\right)$ ou aquele correspondente à resistência à penetração limitante ao desenvolvimento das plantas, segundo critérios propostos por Silva et al. (1994). 
Para a obtenção da $\theta_{\mathrm{CC}}$, substituiu-se o valor do potencial de água no ponto de inflexão na equação 3 (Ferreira \& Marcos, 1983; Mello et al., 2002), enquanto $\theta_{\mathrm{PA}}$ correspondeu ao conteúdo de água no solo em que a porosidade de aeração foi de $0,10 \mathrm{~m}^{3} \mathrm{~m}^{-3}$, segundo a equação: $\theta_{P A}=(V T P-0,1)$ (Silva et al., 2001). $\mathrm{O} \theta_{\mathrm{PMP}}$ foi obtido substituindo-se a tensão correspondente a $-1.500 \mathrm{kPa}$ na equação 3 , e o $\theta_{\mathrm{RP}}$ foi obtido substituindo-se o valor da RP por 2,5 MPa (Camargo \& Alleoni, 1997) nos modelos determinados de RP em função de $\theta$.

O IHO foi determinado pela diferença entre os conteúdos volumétricos de água na capacidade de campo $\left(\theta_{\mathrm{CC}}\right)$ ou porosidade de aeração $\left(\theta_{\mathrm{PA}}\right)$ e no ponto de murcha permanente $\left(\theta_{\mathrm{PMP}}\right)$ ou conteúdo de água na resistência à penetração de $2,5 \mathrm{MPa}$, avaliando-se quais parâmetros foram mais restritivos.

Para a quantificação de poros por tamanho, baseouse na expressão matemática utilizada por Bouma (1991):

$$
D=4 \sigma \operatorname{Cos} \theta / h
$$

sendo $\mathrm{D}$ o diâmetro do poro $(\mu \mathrm{m}) ; \sigma$ a tensão superficial da água $\left(0,727\right.$ bar $\mu \mathrm{m}$ a $\left.20^{\circ} \mathrm{C}\right) ; \theta$ o ângulo de contato entre o menisco e a parede do tubo capilar (considerado como zero) e $\mathrm{h}$ a tensão da água no solo $(\mathrm{kPa})$. O diâmetro do poro foi relacionado a tensões de $-2,-4,-6$, $-33 \mathrm{e}-100 \mathrm{kPa}$ aplicadas às amostras.

Os resultados das análises foram submetidos à análise exploratória dos dados, para a obtenção da distribuição e medidas de dispersão. Nos tratamentos em que foi verificada a normalidade dos erros, os dados foram submetidos à análise de variância e a comparação das médias feita pelo teste de Scott-Knott a $5 \%$, utilizando-se do programa estatístico Sisvar (Ferreira, 2005). A comparação entre os limites superiores e inferiores do IHO foi realizado através das análises do erro-padrão da média.

\section{RESULTADOS E DISCUSSÕES}

No quadro 2, estão apresentadas as distribuições de poros por tamanho e o volume total de poros (VTP) para cada solo e uso estudados. A distribuição de poros por tamanho permitiu identificar onde ocorreram alterações na estrutura dos solos, promovidas pelo uso e manejo. Oliveira et al. (2004), estudando as alterações promovidas por diferentes sistemas de manejo em um Latossolo, também verificou onde ocorrem alterações na estrutura utilizando a avaliação da distribuição de poros por tamanho.

Observa-se maior volume total de poros nas camadas de $0-5$ e $40-45 \mathrm{~cm}$ do LVd e do CXbd cultivados com café em relação à pastagem. Este maior VTP se deve principalmente a alterações nos poros com diâmetro > $145 \mu \mathrm{m}$, mostrando que, nesses solos, esta foi a principal classe de poros afetada pelas pressões aplicadas pelo pisoteio de animais.

Salienta-se que os poros com diâmetro $>50 \mu \mathrm{m}$ (macroporos), em especial os poros com diâmetro $>145 \mu \mathrm{m}$, estão na faixa de tensão em que a condutividade hidráulica é alta (Oliveira, 1968). Parte considerável da água nestes poros drena em pouco tempo (Oliveira et al., 2004), desempenhando importante papel na drenagem interna de água e abastecimento do lençol freático, o que contribui para a manutenção da vazão em nascentes no período da seca. Assim, o maior volume destes poros em área de café mostra que quando bem manejada esta cultura é adequada para uso na APA.

No PVe, a não diferença no volume total de poros nas diferentes camadas, com exceção de uma diferença nos poros $<2,9 \mu \mathrm{m}$ da camada de 20-25 cm (Quadro 2), demonstra similaridade no manejo das culturas em uso neste solo.

Os valores de macroporosidade em todas as camadas dos solos estudados (Quadro 2) não devem ser restritivos ao desenvolvimento das culturas quando se considera o valor de $0,10 \mathrm{~m}^{3} \mathrm{~m}^{-3}$ como referencial (Baver, 1966; Gupta \& Allmaras, 1987). Apesar disso, como já salientado, a manutenção dos poros $>145 \mu \mathrm{m}$ no solo em níveis adequados é de fundamental importância no processo de infiltração de água no solo (Hillel, 2003) e consequentemente na conservação e sustentabilidade do ambiental.

A representação da variação do conteúdo volumétrico de água nos solos nos limites críticos definidos pelo conteúdo de água na capacidade de campo $\left(\theta_{\mathrm{CC}}\right)$, na resistência à penetração de $2,5 \mathrm{MPa}\left(\theta_{\mathrm{RP}}\right)$, na porosidade de aeração de $10 \%\left(\theta_{\mathrm{PA}}\right)$ e no ponto de murcha permanente $\left(\theta_{\mathrm{PMP}}\right)$ está apresentada na figura 2. O intervalo hídrico ótimo (IHO), dos solos cultivados com café e pastagem corresponde a área hachurada. Constataram-se variações do IHO entre o LVd, PVe e CXbd nos usos e profundidades analisadas.

Avaliando-se os limites superiores do IHO, observou-se que o conteúdo de água na capacidade de campo $\left(\theta_{\mathrm{CC}}\right)$ representou o limite superior do IHO em todas as situações estudadas, e a aeração não deve ser limitante ao bom crescimento das plantas. Esses dados corroboram a distribuição de poros por tamanho (Quadro 2), uma vez que, a aeração do solo na capacidade de campo, é realizada pelos macroporos. Avaliando o IHO em um Latossolo Roxo, Tormena et al. (1998) encontraram o conteúdo de água na capacidade de campo como limite superior do IHO em $97 \%$ das amostras.

Verificou-se também (Figura 2) que os valores da $\theta_{\mathrm{CC}}$ apresentaram os menores desvios-padrão visualizados a partir das barras de erros, confirmando a precisão da metodologia para a determinação deste parâmetro. 
Quadro 2. Distribuição de poros $\left(\mathrm{m}^{3} \mathrm{~m}^{-3}\right)$ por tamanho nas camadas (0-5, 20-25 e 40-45 $\left.\mathrm{cm}\right)$ dos solos cultivados com café e pastagem, da microbacia do ribeirão Capituvas, APA Coqueiral

\begin{tabular}{|c|c|c|c|c|c|c|c|}
\hline \multirow{2}{*}{ Uso } & \multicolumn{6}{|c|}{ Diâmetro dos poros $(\mu \mathrm{m})$} & \multirow{2}{*}{$\begin{array}{l}\text { Volume total } \\
\text { de poros }\end{array}$} \\
\hline & $>145$ & $145-73$ & $73-50$ & $50-9,0$ & $9,0-2,9$ & $<2,9$ & \\
\hline \multicolumn{8}{|c|}{ Latossolo Vermelho distrófico típico - LVd } \\
\hline \multicolumn{8}{|c|}{$0-5 \mathrm{~cm}$} \\
\hline Café & $0,14 \mathrm{a}$ & $0,06 \mathrm{a}$ & $0,02 \mathrm{~b}$ & $0,02 \mathrm{a}$ & $0,01 \mathrm{a}$ & $0,24 \mathrm{a}$ & $0,49 \mathrm{a}$ \\
\hline Pastagem & $0,06 \mathrm{~b}$ & $0,03 \mathrm{~b}$ & $0,03 \mathrm{a}$ & $0,03 \mathrm{a}$ & $0,02 \mathrm{a}$ & $0,23 \mathrm{a}$ & $0,40 \mathrm{~b}$ \\
\hline \multicolumn{8}{|c|}{$20-25 \mathrm{~cm}$} \\
\hline Café & $0,16 \mathrm{a}$ & $0,05 \mathrm{a}$ & $0,02 \mathrm{a}$ & $0,02 \mathrm{a}$ & $0,01 \mathrm{a}$ & $0,26 \mathrm{a}$ & $0,52 \mathrm{a}$ \\
\hline Pastagem & $0,12 \mathrm{a}$ & $0,04 \mathrm{a}$ & $0,03 \mathrm{a}$ & $0,03 \mathrm{a}$ & $0,01 \mathrm{a}$ & $0,25 \mathrm{a}$ & $0,48 \mathrm{a}$ \\
\hline \multicolumn{8}{|c|}{$40-45 \mathrm{~cm}$} \\
\hline Café & $0,17 \mathrm{a}$ & $0,04 \mathrm{a}$ & $0,02 \mathrm{a}$ & $0,02 \mathrm{a}$ & $0,00 \mathrm{a}$ & $0,26 \mathrm{a}$ & $0,51 \mathrm{a}$ \\
\hline Pastagem & $0,12 \mathrm{~b}$ & $0,02 \mathrm{a}$ & $0,02 \mathrm{a}$ & $0,02 \mathrm{a}$ & $0,00 \mathrm{a}$ & $0,28 \mathrm{a}$ & $0,46 \mathrm{~b}$ \\
\hline \multicolumn{8}{|c|}{ Argissolo Vermelho eutrófico típico - PVe } \\
\hline \multicolumn{8}{|c|}{$0-5 \mathrm{~cm}$} \\
\hline Café & $0,08 \mathrm{a}$ & $0,03 \mathrm{a}$ & $0,02 \mathrm{a}$ & $0,03 \mathrm{a}$ & $0,02 \mathrm{a}$ & $0,26 \mathrm{a}$ & $0,44 \mathrm{a}$ \\
\hline Pastagem & $0,09 \mathrm{a}$ & $0,02 \mathrm{a}$ & $0,02 \mathrm{a}$ & $0,02 \mathrm{a}$ & $0,03 \mathrm{a}$ & $0,25 \mathrm{a}$ & $0,43 \mathrm{a}$ \\
\hline \multicolumn{8}{|c|}{$20-25 \mathrm{~cm}$} \\
\hline Café & $0,14 \mathrm{a}$ & $0,04 \mathrm{a}$ & $0,02 \mathrm{a}$ & $0,02 \mathrm{a}$ & $0,01 \mathrm{a}$ & $0,26 \mathrm{a}$ & $0,49 \mathrm{a}$ \\
\hline Pastagem & $0,12 \mathrm{a}$ & $0,03 \mathrm{a}$ & $0,02 \mathrm{a}$ & $0,02 \mathrm{a}$ & $0,02 \mathrm{a}$ & $0,24 \mathrm{~b}$ & $0,45 \mathrm{~b}$ \\
\hline \multicolumn{8}{|c|}{$40-45 \mathrm{~cm}$} \\
\hline Café & $0,10 \mathrm{a}$ & $0,04 \mathrm{a}$ & $0,02 \mathrm{a}$ & $0,02 \mathrm{a}$ & $0,00 \mathrm{a}$ & $0,28 \mathrm{a}$ & $0,46 \mathrm{a}$ \\
\hline Pastagem & $0,08 \mathrm{a}$ & $0,04 \mathrm{a}$ & $0,02 \mathrm{a}$ & $0,03 \mathrm{a}$ & $0,01 \mathrm{a}$ & $0,25 \mathrm{a}$ & $0,43 \mathrm{a}$ \\
\hline \multicolumn{8}{|c|}{ Cambissolo Háplico distrófico típico - CXbd } \\
\hline \multicolumn{8}{|c|}{$0-5 \mathrm{~cm}$} \\
\hline Café & $0,13 \mathrm{a}$ & $0,04 \mathrm{a}$ & $0,03 \mathrm{a}$ & $0,03 \mathrm{a}$ & $0,01 \mathrm{a}$ & $0,24 \mathrm{a}$ & $0,48 \mathrm{a}$ \\
\hline Pastagem & $0,08 \mathrm{~b}$ & $0,05 \mathrm{a}$ & $0,02 \mathrm{a}$ & $0,02 \mathrm{~b}$ & $0,01 \mathrm{a}$ & $0,22 \mathrm{a}$ & $0,40 \mathrm{~b}$ \\
\hline \multicolumn{8}{|c|}{$20-25 \mathrm{~cm}$} \\
\hline Café & $0,14 \mathrm{a}$ & $0,03 \mathrm{a}$ & $0,02 \mathrm{a}$ & $0,02 \mathrm{a}$ & $0,00 \mathrm{a}$ & $0,28 \mathrm{a}$ & $0,49 \mathrm{a}$ \\
\hline Pastagem & $0,09 \mathrm{a}$ & $0,04 \mathrm{a}$ & $0,02 \mathrm{a}$ & $0,03 \mathrm{a}$ & $0,02 \mathrm{a}$ & $0,23 \mathrm{a}$ & $0,43 \mathrm{~b}$ \\
\hline \multicolumn{8}{|c|}{$40-45 \mathrm{~cm}$} \\
\hline Café & $0,15 \mathrm{a}$ & $0,02 \mathrm{a}$ & $0,02 \mathrm{a}$ & $0,01 \mathrm{a}$ & $0,00 \mathrm{a}$ & $0,28 \mathrm{a}$ & $0,48 \mathrm{a}$ \\
\hline Pastagem & $0,11 \mathrm{~b}$ & $0,04 \mathrm{a}$ & $0,02 \mathrm{a}$ & $0,01 \mathrm{a}$ & $0,01 \mathrm{a}$ & $0,25 \mathrm{a}$ & $0,44 \mathrm{~b}$ \\
\hline
\end{tabular}

Dentro de cada solo e cada profundidade, médias seguidas pela mesma letra, nas colunas, não diferem entre si pelo teste de ScottKnott a $5 \%$. Os diâmetros de 145,$0 ; 73,0 ; 50,0 ; 9,0 ; 2,9 \mu \mathrm{m}$ dos poros estão relacionados às tensões de $-2,-4,-6$, $-33 \mathrm{e}-100 \mathrm{kPa}$ aplicadas às amostras.

$\mathrm{Na}$ avaliação dos limites inferiores do IHO, observou-se que o conteúdo de água no ponto de murcha permanente $\left(\theta_{\mathrm{PMP}}\right)$, com exceção do PVe, tem valores crescentes de restrições com a maior profundidade do solo. O conteúdo de água na resistência à penetração de $2,5 \mathrm{MPa}\left(\theta_{\mathrm{RP}}\right)$ apresentouse como limite inferior do IHO em camadas onde foram observadas restrições ao crescimento das raízes, isto é, camadas compactadas ou adensadas (Tormena et al., 1998). Assim, a $\theta_{\mathrm{RP}}$ pode ser um indicativo do grau de compactação ou adensamento da camada do solo, uma vez que ocorre aumento da RP com o aumento da Ds, fato este atribuído ao efeito da matriz do solo ocasionado pela compactação, aliado ao aumento da coesão causado pela ação da umidade do solo entre as partículas que ficam mais próximas à medida que o solo é compactado ou adensado (Sojka et al., 2001).

Na camada de $0-5 \mathrm{~cm}$ do LVd e PVe, ambos sob pastagem, foram observados menores valores de IHO, e, nesses casos, a resistência à penetração, denotada pela $\theta_{\mathrm{RP}}$ (Figura 2), foi o parâmetro que representou o limite inferior do IHO. Devido à proximidade de $\theta_{\mathrm{RP}} \mathrm{e}$ $\theta_{\mathrm{PMP}}$, salienta-se que o resultado no LVd se deve mais à baixa capacidade de retenção de água nesta classe de solo, o que é função do elevado grau de intemperismo (Resende et al., 2007) indicado pelos baixos valores de Ki e Kr (Quadro 1).

No PVe, a limitação foi atribuída à elevada resistência do solo à penetração, justificando-se esse resultado pelo estado de degradação em que se encontra o solo. Isto ocorre devido a maior exploração agrícola desta classe que apresenta maior fertilidade natural, ao superpastoreio constatado pela falta de cobertura vegetal em muitos pontos e à presença marcante de erosão do tipo laminar. Ressalta-se que o adensamento natural dos horizontes subsuperficiais, decorrentes da translocação de argila dos horizontes superiores, contribuíram para o aumento da resistência à penetração em profundidade no PVe (Giarola et al., 2003; Embrapa, 2006, Suzuki et al., 2008). 


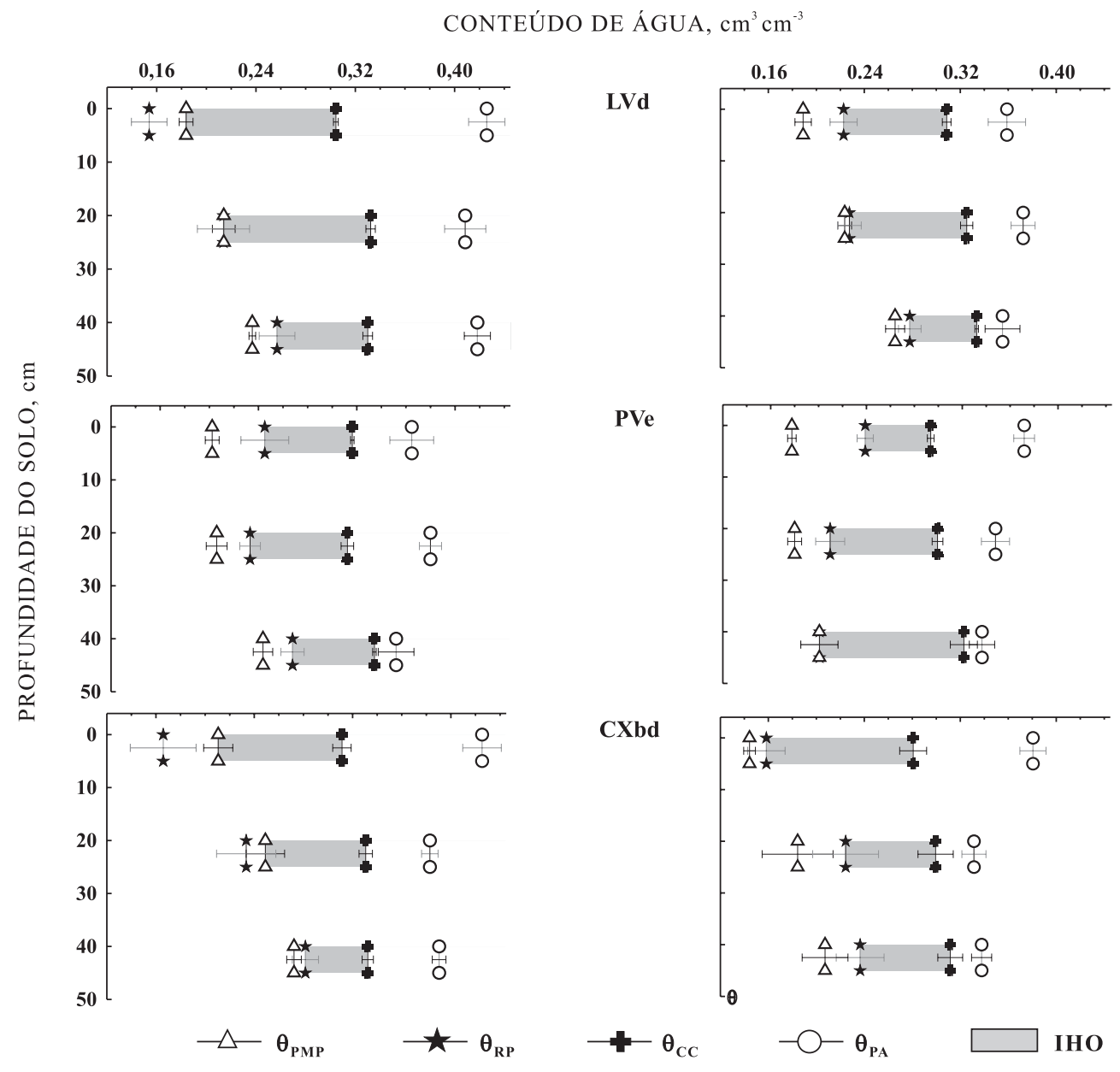

Figura 2. Intervalo hídrico ótimo (IHO) de três camadas do Latossolo Vermelho distrófico típico (LVd), Argissolo Vermelho eutrófico típico (PVe) e Cambissolo Háplico distrófico típico (CXbd), cultivados com café (esquerda) e pastagem (direita) na microbacia do ribeirão Capituvas, APA Coqueiral.

No PVe cultivado com café e pastagem e LVd cultivado com pastagem, verificou-se redução da qualidade estrutural quantificada pela substituição do $\theta_{\mathrm{PMP}}$ pelo $\theta_{\mathrm{RP}}$ como limite inferior do IHO na camada de $0-5 \mathrm{~cm}$ destes solos. Essa redução da qualidade estrutural diminui a quantidade de água potencialmente disponível, sendo os efeitos observados até em camadas mais profundas no caso do PVe sob café.

Não foram verificadas diferenças entre os poros com diâmetro $<50 \mu \mathrm{m}$, que são microporos, responsáveis pelo armazenamento de água potencialmente disponível para as plantas, corroborando com Oliveira et al. (2004). Porém, o IHO variou bastante, sendo, em média $\mathrm{LVd}>\mathrm{CXbd}>\mathrm{PVe}$ (Figura 2). O cálculo do armazenamento de água até a profundidade de $60 \mathrm{~cm}$, utilizando o IHO médio das três camadas para a área cultivada com café e pastagem apresenta, respectivamente, os seguintes valores: 58 e $46 \mathrm{~mm}$ para o $\mathrm{LVd}$; 44 e $52 \mathrm{~mm}$ para o CXbd; 40 e $48 \mathrm{~mm}$ para o PVe.

Observando a figura 2 , verifica-se que a LVd e o CXbd sob cafezal têm recebido manejo conservacionista, tendo em vista, com base nos parâmetros analisados, provável ausência de limitação física ao bom desenvolvimento do sistema radicular da cultura, sendo a $\theta_{\mathrm{PMP}}$ o limite inferior e a $\theta_{\mathrm{CC}} \mathrm{o}$ limite superior do IHO. Isso demonstra a possibilidade de convivência do homem em áreas destinadas à conservação ambiental, desde que práticas de plantio em nível, terraceamento e culturas de cobertura sejam adotadas.

No PVe, observou-se que a pastagem apresentou maior IHO na profundidade de $40-45 \mathrm{~cm}$ em comparação com as camadas superficiais e todas as profundidades analisadas na área sob cafezal (Figura 2). Esse fato foi atribuído à compactação do solo promovida pelo pisoteio de animais na camada superficial dos solos em área sob pastagem. Há indicações de que os animais podem exercer pressões no solo superiores inclusive a de tratores de médio porte (Betteridge et al., 1999), reduzindo o espaço poroso para armazenamento da água. Para este mesmo solo, o maior valor do IHO em profundidade é atribuído à preservação da estrutura e à maior quantidade de argila. Na área sob café no PVe, que 
também encontra-se degradada, é provável que o manejo inadequado, com ausência de proteção do solo, tenha afetado mesmo a camada de $40-45 \mathrm{~cm}$.

Os solos cultivados com café, de modo geral, apresentaram maior conteúdo de água potencialmente disponível na superfície, e este diminui com a profundidade do solo, com exceção ao PVe (Figura 2). A análise do IHO é importante por representar as restrições que os solos têm ao bom desenvolvimento das plantas (Silva et al., 1994). Assim, solos com alta capacidade de armazenamento de água, sem restrições à penetração de raízes e com aeração suficiente são potenciais para a manutenção da capacidade produtiva e sustentabilidade ambiental na microbacia do ribeirão Capituvas, APA Coqueiral.

\section{CONCLUSÕES}

1. O estudo do intervalo hídrico ótimo pode ser utilizado na quantificação da disponibilidade hídrica dos solos submetidos a diferentes usos e manejos.

2. Para os usos estudados, o PVe apresentou a menor disponibilidade hídrica comparado ao LVd e ao $\mathrm{CXbd}$, resultando em uma baixa qualidade física e no comprometimento das atividades produtivas e da sustentabilidade ambiental desse solo.

3. Áreas cultivadas com café e bem manejadas apresentam melhor qualidade física do solo quando comparadas a áreas cultivadas com pastagem, desempenhando significativa importância na manutenção e fluxo da água nos solos da microbacia do ribeirão Capituvas, APA Coqueiral.

\section{LITERATURA CITADA}

BAVER, L.D. Soil physics. 3.ed. New York, J. Wiley, 1966. 489p.

BETTERIDGE, K.; MACKAY, A.D.; SHEPHERD, T.G.; BARKER, D.J.; BUDDING, P.J.; DEVANTIER, B.P. \& COSTALL, D.A. Effect of cattle and sheep treading on surface configuration of a sedimentary hill soil. Aust. J. Soil Res., 37:743-760, 1999.

BEUTLER, A.N.; CENTURION, J.F.; SILVA, A.P.; CENTURION, M.A.P.C.; LEONEL, C.L. \& FREDDI, O.S. Soil compaction by machine traffic and least limiting water range related to soybean yield. Pesq. Agropec. Bras., 43:1591-1600, 2008

BOUMA, J. Influence of soil macroporosity on environmental quality. Adv. Agron., 46:1-37, 1991.

BRASIL. Ministério da Agricultura. Centro Nacional de Ensino e Pesquisas Agronômicas. Levantamento de reconhecimento dos solos da região sob influência do reservatório de Furnas: Contribuição à carta de solos, + map, scale 1:250,000. Rio de Janeiro, 1962. 462p. (Boletim do Serviço Nacional de Pesquisas Agronômicas, 13)
CAMARGO, O.A. \& ALLEONI, L.R.F. Compactação do solo e o desenvolvimento de plantas. Piracicaba, Escola Superior de Agricultura Luiz de Queiroz, 1997. 132p.

DEXTER, A.R. Soil physical quality: Theory, effects of soil texture, density, and organic matter, and effects on root growth. Part 1. Geoderma, 120:201-214, 2004.

DIAS JUNIOR, M.S. Compression of three soils under longterm tillage and wheel traffic. East Lansing, Michigan State University, 1994. 114p. (Tese de Doutorado).

DOURADO NETO, D.; NIELSEN, D.R.; HOPMANS, J.W.; REICHARDT, K. \& BACCHI, O.O.S. Software to model soil water retention curves (SWRC, version 2.0). Sci. Agric., 57:191-192, 2000.

EMPRESA BRASILEIRA DE PESQUISA AGROPECUÁRIA EMBRAPA. Centro Nacional de Pesquisa de Solos. Manual de métodos de análise de solo. 2.ed. Rio de Janeiro, 1997. 212p.

EMPRESA BRASILEIRA DE PESQUISA AGROPECUÁRIA EMBRAPA. Centro Nacional de Pesquisas de Solos. Sistema brasileiro de classificação de solos. 2.ed. Rio de Janeiro, Embrapa Solos; Brasília, Sistema de Produção de Informação, 2006. 306p.

EMPRESA DE ASSISTÊNCIA TÉCNICA E EXTENSÃO RURAL DO ESTADO DE MINAS GERAIS - EMATER. Área de proteção ambiental do Município de Coqueiral. Belo Horizonte, Unidade de Consultoria e Projetos, 2002.

FERREIRA, D.F. Estatística básica. Lavras, Universidade Federal de Lavras, 2005. 654p.

FERREIRA, M.M. \& MARCOS, Z.Z. Estimativa da capacidade de campo de Latossolo Roxo Distrófico e Regossolo através do ponto de inflexão da curva característica de umidade. Ci. Prática, 7:96-101, 1983.

GIAROLA, N.F.B.; SILVA, A. P.; IMHOFF, S.C. \& DEXTER, A.R. Contribution of natural soil compaction on hardsetting behavior. Geoderma,113:95-108, 2003.

GUPTA, S.C. \& ALLMARAS, R.R. Models to asses the susceptibility of soils to excessive compaction. Adv. Soil Sci., 6:65-100, 1987.

HILLEL, D. Introduction to environmental soil physics. New York, Academic Press, 2003. 494p.

LAPEN, D.R.; TOPP, G.C.; GREGORICH, E.G. \& CURNOE, W.E. Least limiting water range indicators of soil quality and corn production, eastern Ontario, Canada. Soil Till. Res., 78:151-170, 2004.

MELLO, C.R.; OLIVEIRA, G.C.; DIAS JUNIOR, M.S. \& RESCK, D.V.S. Estimativa da capacidade de campo baseada no ponto de inflexão da curva característica gerada por regressão polinomial cúbica. Ci. Agrotecnol., 26:836-841, 2002

OLIVEIRA, G.C.; DIAS JUNIOR, M.S.; CURI, N. \& RESCK, D.V.S. Caracterização química e físico-hídrica de um Latossolo Vermelho após 20 anos de manejo e cultivo do solo. R. Bras. Ci. Solo, 28:335-344, 2004. 
OLIVEIRA, L.B. Determinação da macro e microporosidade pela mesa de tensão em amostras de solo com estrutura indeformada. Pesq. Agropec. Bras., 3:197-200, 1968.

REICHERT, J.M.; SUZUKI, L.E.A.S. \& REINERT, D.J. Compactação do solo em sistemas agropecuários e florestais: Identificação, efeitos, limites críticos e mitigação. In: CERETTA, C.A.; SILVA, L.S. \& REICHERT, J.M., orgs. Tópicos em ciência do solo. Viçosa, MG, SBCS, 2007. v.5. p.49-134.

REINERT, D.J. \& REICHERT, J.M. Coluna de areia para medir a retenção de água no solo - protótipos e teste. Ci. Rural, 36:1931-1935, 2006.

RESENDE, M.; CURI, N.; REZENDE, S.B. \& CORREAA, G.F. Pedologia: Base para distinção de ambientes. 5.ed. Lavras, Universidade Federal de Lavras, 2007. 322p.

SANTOS, R.D.; LEMOS, R.C.; SANTOS, H.G.; KER, J.C. \& ANJOS, L.H.C. Manual de descrição e coleta de solo no campo. 5.ed. Viçosa, MG, Sociedade Brasileira de Ciência do Solo, 2005. 92p.

SEVERIANO, E.C.; OLIVEIRA, G.C.; CURI, N. \& DIAS JUNIOR, M.S. Potencial de uso e qualidade estrutural de dois solos cultivados com cana-de-açúcar em Goianésia (GO). R. Bras. Ci. Solo, 33:159-168, 2009.

SIGMA PLOT. Scientific Graphing Software: versão 10.0. San Rafael, Hearne Scientific Software, 2006.

SILVA, A.P. \& KAY, B.D. The sensitivity of shoot growth to the least limiting water range of soils. Plant Soil, 184:323329, 1996.
SILVA, A.P. \& KAY, B.D. Estimating the least limiting water range of soils from properties and management. Soil Sci. Soc. Am. J., 61:877-883, 1997.

SILVA, A.P.; KAY, B.D. \& PERFECT, E. Characterization of the least limiting water range of soils. Soil Sci. Soc. Am. J., 58:1775-1781, 1994.

SILVA, A.P.; NADLER, A. \& KAY, B.D. Factors contributing to temporal stability in spatial patterns of water content in the tillage zone. Soil Till. Res., 58:207-218, 2001.

SOJKA, R.E.; BUSSCHER, W.J. \& LEHRSCH, G.A. In situ strength, bulk density, and water content relations of a durinodic xeric haplocalcid soil. Soil Sci., 166:520-529, 2001.

SUZUKI, L.E.A.S.; REINERT, D.J.; REICHERT, J.M. \& LIMA, C.L.R. Estimativa da suscetibilidade à compactação e do suporte de carga do solo com base em propriedades físicas de solos do Rio Grande do Sul. R. Bras. Ci. Solo, 32:963973, 2008.

TORMENA, C.A.; ARAÚJO, M.A.; FIDALSKI, J. \& COSTA, J.M. Variação temporal do intervalo hídrico ótimo de um Latossolo Vermelho distroférrico em sistemas de plantio direto. R. Bras. Ci. Solo, 31:211-219, 2007.

TORMENA, C.A.; ROLOFF, G. \& SÁ, J.C. Propriedades físicas do solo sob plantio direto influenciadas por calagem, preparo inicial e tráfego. R. Bras. Ci. Solo, 22:301-309, 1998.

van GENUCHTEN, M.T. A closed-form equation for predicting the hydraulic conductivity of unsaturated soils. Soil Sci. Soc. Am. J., 44:892-898, 1980. 